Journal of Bangladesh Academy of Sciences, Vol. 35, No. 1, 7-17, 2011

\title{
A STUDY ON SOME PHYSICAL PARAMETERS RELATED TO IMAGE QUALITY AND RADIATION SAFETY IN DIAGNOSTIC RADIOLOGY
}

\author{
MAHFUZA BEGUM ${ }^{1}$, A. S. MOLLAH ${ }^{2}$, M. A. ZAMAN ${ }^{3}$, M. HAQ ${ }^{4}$ AND \\ A. K. M. MIZANUR RAHMAN ${ }^{5}$ \\ Institute of Nuclear Science and Technology, Atomic Energy Research Establishment, \\ BAEC, Ganakbari, Savar, Dhaka-1349, Bangladesh
}

\begin{abstract}
Different essential radiographic parameters were studied in order to assess radiographic image quality ensuring reduction of radiation exposure in some diagnostic X-ray facilities of Bangladesh. Different parameters for developing and fixing liquid were investigated in order to eliminate improper film processing techniques. General information about intensifying screen, radiography and mammography film was also collected. X-ray tube voltage, output radiation dose and exposure time for diagnostic $\mathrm{X}$-ray machines were tested to achieve significant dose reduction without loss of diagnostic information. It is found that output radiation dose varies in different diagnostic X-ray installations. 70\% X-ray installations achieve the recommended value for tube voltage while $87.5 \%$ measure the exposure time appropriately. Radiation dose level at patient waiting room, dark room and around control panel was also measured. About 92.5, 85 and 77.5\% installations show their results within the acceptance limit at these positions respectively which provide radiation safety for patients, workers and public in diagnostic radiology.
\end{abstract}

Key words: Image quality, Radiation safety, Developing liquid, Fixing liquid, pH value

\section{INTRODUCTION}

Use of X-rays in diagnostic radiology has been continuing to develop and expand. $\mathrm{X}$-ray has now become a probe for routine and primary mode of investigation in the health care. The diagnostic X-ray examinations are the most frequent and significant source of medical exposure for the world population (Muhogora and Nyanda 2001). The use of ionizing radiation is not without risk, though the use provides some benefit to patient's health. All radiation exposures to diagnostic X-rays must be justified and optimized on the basis of the benefits and risks to the patient. The aim of an X-ray examination is to produce an image of the patient's organs of sufficient quality to provide adequate diagnostic information. Therefore irradiation of the patient should be kept to the lowest limit consistent with the clinical needs of each case (Hamed et al. 1999, Warren-

\footnotetext{
${ }^{1}$ Health Physics and Radioactive Waste Management Unit, INST, AERE, Bangladesh Atomic Energy Commission.

${ }^{2}$ Bangladesh Atomic Energy Commission, Agargaon, Dhaka, Bangladesh.

${ }^{3}$ Physics Department, Jahangirnagar University, Savar, Dhaka, Bangladesh.

${ }^{4}$ Physics Department, Bangladesh University of Engineering and Technology, Dhaka, Bangladesh.

${ }^{5}$ Centre for Nuclear Medicine and Ultrasound, DMCH.
} 
Forward and Mckeeney 1992). To satisfy these requirements of radiation protection, it is necessary to know type of X-ray examinations carried out and their number along with the physical parameters employed and the radiation doses delivered to patients.

For the purpose of verifying the actual situation of the health services many countries have developed their own programmes. Surveys have been conducted in many countries using essentially the same techniques to estimate the absorbed doses delivered to patients during X-ray examinations (Freitas and Yoshimura 2003)]. But in Bangladesh radiation safety aspect is not adequately cared in the diagnostic X-ray installations. This causes increase in unwanted personal dose as well as population dose. Time and temperature for developing and fixing liquid and $\mathrm{pH}$ value also affect diagnostic image quality. Ideally, developing solution should be basic i.e. $\mathrm{pH}$ value is between 7 and 14 and fixing solution should be acidic i.e. $\mathrm{pH}$ value is between 0 and 7. Diagnostic X-ray film processing time depends on temperature of the chemical solutions. In order to obtain good quality image the film should be removed from the developer after the time which is required for that temperature. To obtain proper quality images strength, temperature and time for processing solutions should be controlled strictly. Radiation protection survey of diagnostic X-ray installations is also essential to ensure that radiation doses received by radiation workers are within the recommended dose limit. X-ray tube voltage is another most important radiological factor which affects the intensity of the X-ray output as well as contrast in the image. Its periodic check is warranted. The measurement of exposure time and output radiation dose are also required to obtain proper quality radiograph with reduced radiation exposure to patients. Therefore, it should be assessed regularly to improve equipment performance and to ensure the safe and proper operation of the X-ray system in diagnostic radiology units. In case of radiological examination, irradiation of the patient should be minimized by using the best available techniques.

\section{MATERIALS AND METHODS}

To minimize radiation hazard in the field of diagnostic radiology, various important radiographic parameters are assessed according to quality control protocol from different diagnostic X-ray installations. These installations are shown by code numbers. The measured parameter values are then compared to the relevant acceptance limits. The measuring methods are given below.

Film processing technique provides a major role in diagnostic image quality and patient dose optimization (Schandrof and Tetteh 1998). Improper film processing technique is the most frequent cause of poor X-ray image quality. This is due to the large number of variables, such as concentration level, temperature and time of the processing chemicals. In this case temperature, $\mathrm{pH}$ value, and time were recorded for developing and fixing liquid used in different diagnostic $\mathrm{X}$-ray installations. $\mathrm{pH}$ value for developing and fixing liquid were determined by using $\mathrm{pH}$ electrode (Model PE -03). 
Manual processing is prone to great fluctuations in quality unless rigid adherence to the time/temperature method is practised. In this case, with every increment in temperature of the developer by $1^{\circ} \mathrm{C}$ in the range of $15-23^{\circ} \mathrm{C}$, developing time decreases by 0.5 minute. Normal range of developing time is $(5-3)$ minutes at $19-23^{\circ} \mathrm{C}$. With special precautions the temperature range can be extended to $25^{\circ} \mathrm{C}$, using 2 minutes for the development. Shorter developing times than 2 minutes cannot be maintained properly in routine work (Staffan et al. 2003).

The values of $\mathrm{pH}$ for the solutions were measured by stirring the electrode in the sample and readings were taken after it became stabilized. Between readings the electrode of the $\mathrm{pH}$ meter was placed in a beaker containing $\mathrm{pH} 4$ buffer or distilled water which was kept at the same temperature of the samples in order to provide correct values for temperature effects. Temperature and time were determined for developing and fixing liquid by using digital thermometer and timer. The measured parameter values were compared to the relevant acceptance limits to ensure proper quality diagnostic images.

Radiation dose levels at patient waiting room, dark room and control panel (Fig.1) were determined in terms of dose rate $(\mu \mathrm{Sv} / \mathrm{hr})$. The study was performed by using Geiger Muller survey meter when the X-ray tubes were operated. The measured parameters were compared with the given values in published guidelines (ICPR 1990).

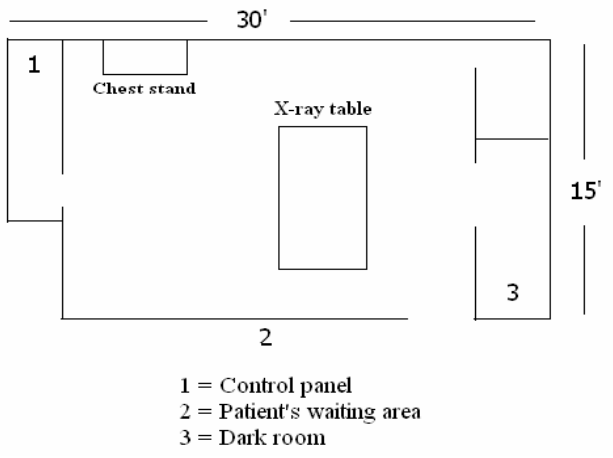

Fig. 1. Layout of a typical X-ray room.

A small change in $\mathrm{X}$-ray tube voltage $(\mathrm{kVp})$ has greater effect on the final radiographic images. Therefore, it should be checked periodically. In the present study, the accuracy of $\mathrm{kVp}$ between set - and measured values were investigated in different diagnostic X-ray installations by using Digital kVp meter (Model 07-494). To carry out the work a $\mathrm{kVp}$ meter was placed on a couch at $100 \mathrm{~cm}$ from the X-ray tube target and exposure was made on its surface. The measured $\mathrm{kVp}$ and set $\mathrm{kVp}$ were compared. It has greater effect on output radiation exposure and therefore its tolerance criterion is stricter which is $\pm 5 \%$ from the set value at control panel (Rehani 1995). 
Agreement between set exposure time value and measured value is very essential as it directly affects the mAs and hence the amount of radiation emitted. In the present experiment, exposure time and output radiation dose for diagnostic X-ray machine were investigated by a dosimeter.

A questionnaire was prepared and used to collect radiographic information from 100 different government and private diagnostic X-ray installations. The information regarding intensifying screen, diagnostic X-ray and mammography film was collected by visiting 100 different diagnostic X-ray installations from directly involved persons of the installations through some questions and observations.

\section{RESULTS AND DISCUSSION}

In the present investigation, $\mathrm{pH}$ value, temperature of the developing liquid, developing time and room temperature were recorded for each developing liquid used in different diagnostic X-ray installations. The results are shown graphically in Figs 2 (a), (b), (c) and (d), respectively. Ideally, developing solution of the diagnostic X-ray film should be basic i.e. pH value is between 7 and 14. But all the measured values in the present study were not so. Sixty per cent developing liquids were basic and remaining $40 \%$ crossed the limit. As a result $40 \%$ X-ray installations failed to achieve the proper concentration level of the processing chemical. Diagnostic X-ray film developing time depends on the temperature of the chemical solutions. Therefore, to obtain good quality image the film should be removed from the developer after the time which is required for that specific temperature but in this case all the installations exceeded the temperature limit and thereby also crossed the developing time limit. There is large variation for time and temperature of developing liquid in different diagnostic X-ray installations which provide variations in diagnostic image quality.

Different diagnostic X-ray installations should be properly maintain the concentration level of the processing chemical, developing time and temperature to reduce poor quality diagnostic images.

Variation in image quality may be caused by changes in temperature, $\mathrm{pH}$ value and time in fixing liquid. It was found that $93.75 \% \mathrm{X}$-ray installations provided acidic fixing solution and $6.25 \%$ provided solution whose characteristics were out of the limit (Fig. 3). It was also found that there was no installation to follow time-temperature method of film processing. The installations should minimize their improper film processing techniques with appropriate precautions and they should also change processing solutions regularly because they become weaker with age and use.

Most of the diagnostic X-ray installations (42.61\%) had a tendency to use "250intensify screen speed" and 36.52, 8.69, 5.22, 3.48, 1.74 and $1.74 \%$ X-ray installations 
used 400, 500, 200, 800, 700 and 100 "intensifying screen speed" respectively (Fig. 4). $56.44 \%$ intensifying screens were made in Japan, $34.65 \%$ were in China and $8.91 \%$ were made in Germany. In this case, maximum installations used "Okamoto" intensifying screen which were made in Japan and 250-intensifying screen speed. They should use proper quality high speed intensifying screen to reduce radiation exposure and thereby it will be possible to improve image quality and radiation safety in diagnostic radiology.

Most of the diagnostic X-ray installations (64.1\%) used Fuji films which can be preserved for a long time and 26.49, 6.84 and 2.57\% installations used Konica, Kodak and Agfa plain radiographic films, respectively (Fig. 5). It was also found that maximum plain radiographic films $(90.59 \%)$ were made in Japan and a few $(2.57 \%)$ were made in Germany.

Only 8 diagnostic X-ray installations out of 100 had installed mammographic machines. Most of the diagnostic X-ray installations (55.60\%) used Fuji mammographic films because images in these films are not damaged easily and some (44.4\%) used Kodak films (Fig. 6). Maximum (55.60\%) mammography films were made in Japan and $44.40 \%$ were made in the U. S. A.

In case of tube voltage measurement tolerance limit is set at $\pm 5 \%$ from the set value at control-panel.

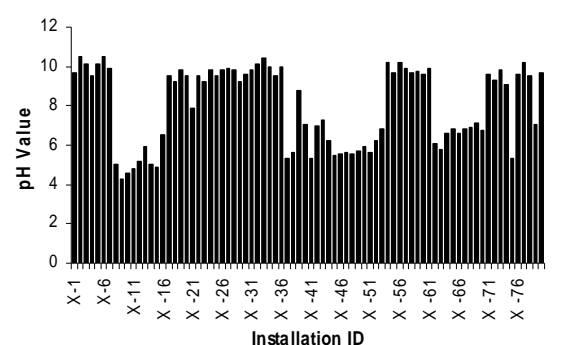

(a)

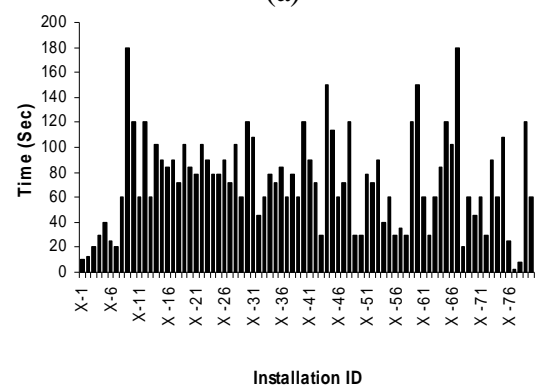

(c)

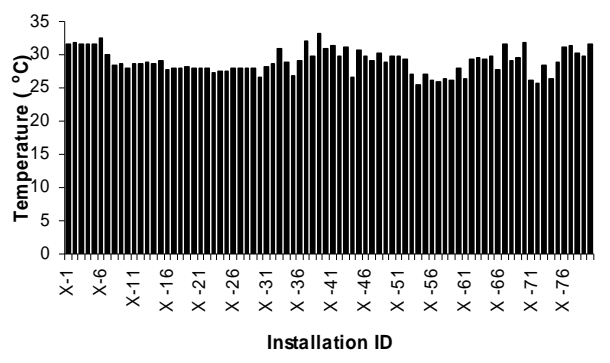

(b)

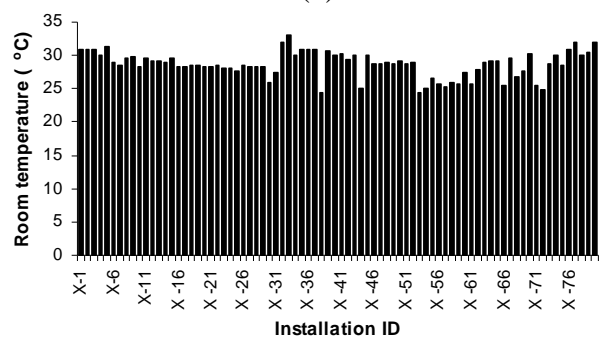

(d)

Fig. 2. Variation of (a) $\mathrm{pH}$ value of film developing liquid. (b) Temperature $\left({ }^{\circ} \mathrm{C}\right)$ of developing liquid. (c) Developing time of diagnostic X-ray film. (d) Room temperature of developing liquid used in different X-ray installations. 


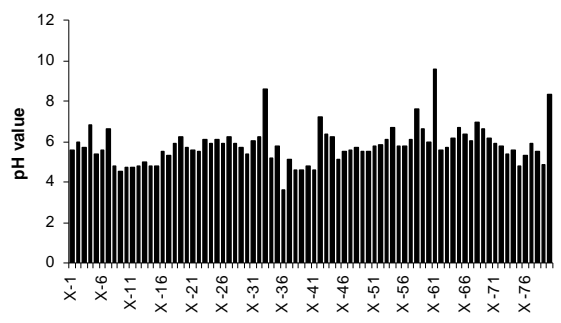

Installation ID

(a)

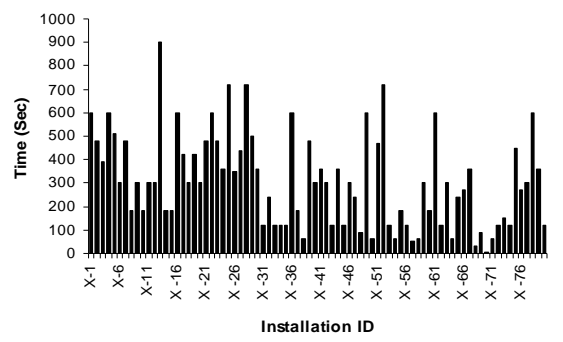

(c)

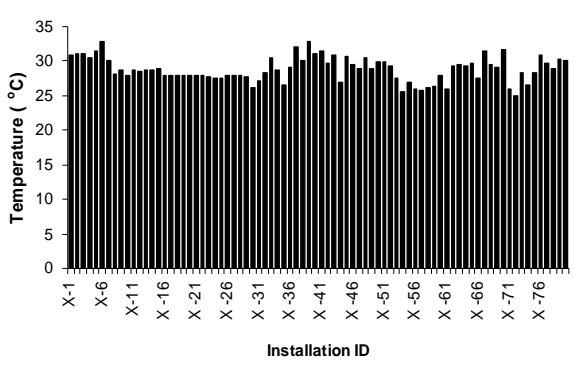

(b)

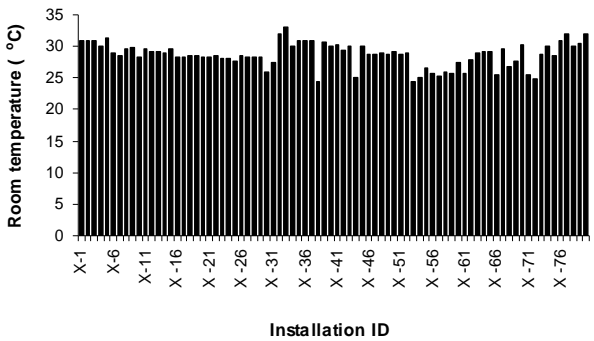

(d)

Fig. 3. (a) Variation of (a) $\mathrm{pH}$ value of film fixing liquid. (b) Temperature $\left({ }^{\circ} \mathrm{C}\right.$ ) of fixing liquid. (c) Fixing time of diagnostic X-ray film. (d) Room temperature of fixing liquid used in different X-ray installations.

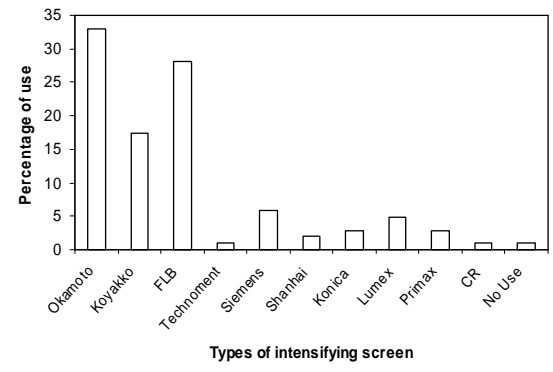

(a)

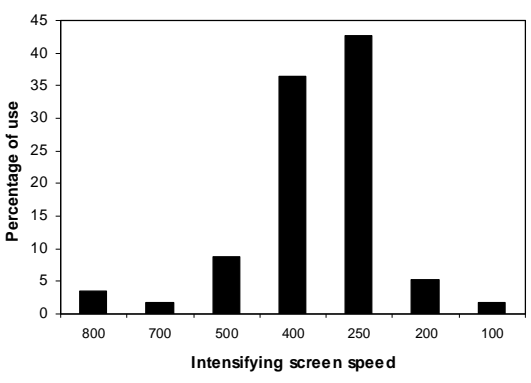

(b)

Fig. 4. (a) Percentage use of different types intensifying screen. (b) Variation of intensifying screen speed.

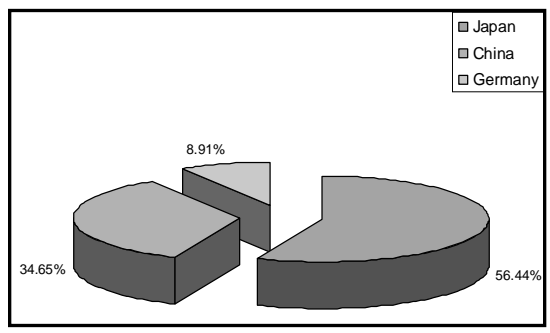

(c)

Fig. 4. (c) Origin of country for intensifying screen. 


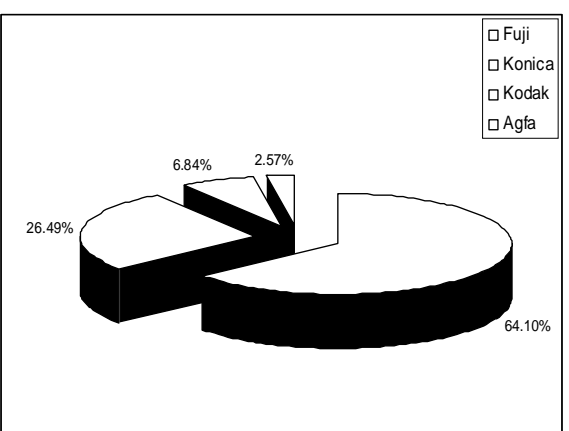

(a)

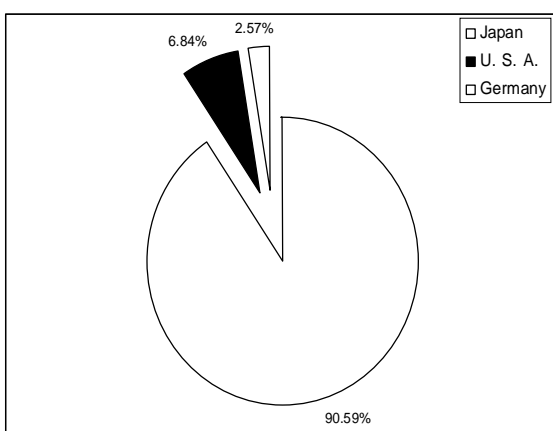

(b)

Fig. 5. (a) Type wise distribution of diagnostic film. (b) Origin of country for diagnostic plain radiography film.

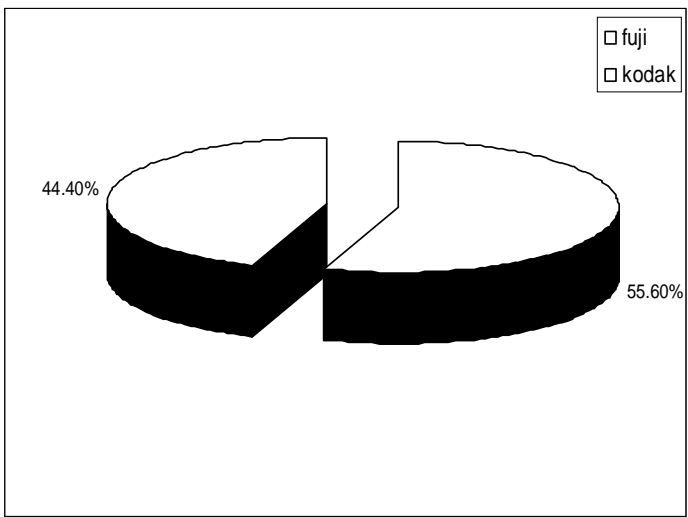

(a)

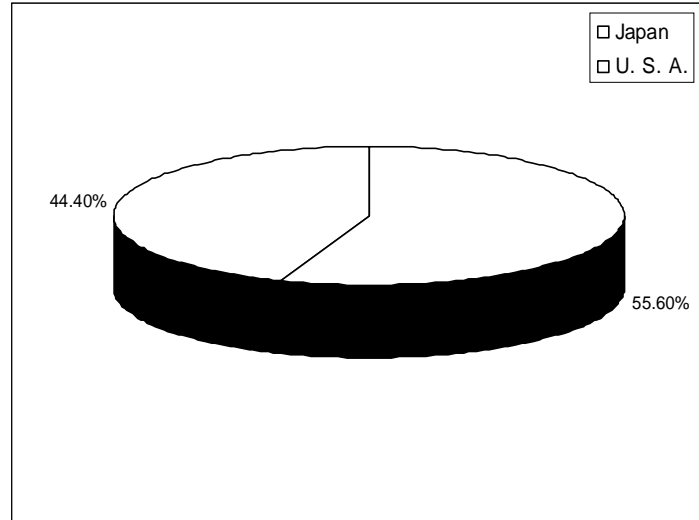

(b)

Fig. 6. (a) Type wise distribution of mammography film. (b) Origin of country for mammography film. 
Journal of Bangladesh Academy of Sciences, Vol. 35, No. 1, 7-17, 2011

Table 1. Data on tube voltage, out put dose and exposure time for different diagnostic X-ray machines.

\begin{tabular}{|c|c|c|c|c|c|c|c|c|c|}
\hline \multirow{2}{*}{$\begin{array}{l}\text { Serial } \\
\text { No. }\end{array}$} & \multirow{2}{*}{$\begin{array}{l}\text { Installation } \\
\text { ID }\end{array}$} & \multicolumn{2}{|c|}{ Tube voltage $(\mathrm{kVp})$} & \multirow{2}{*}{$\begin{array}{c}\text { Exposure (mGy) } \\
\text { Out put dose }\end{array}$} & \multicolumn{2}{|c|}{ Exposure time (mSec) } & \multicolumn{3}{|c|}{ Radiation dose level $(\mu \mathrm{Sv} / \mathrm{hr})$} \\
\hline & & Set value & Measured value & & Set value & Measured value & Patient waiting room & Dark room & Control panel \\
\hline 1 & $\mathrm{X}-1$ & 60 & 60 & 4.03 & 187 & 187 & 0.36 & 0.13 & 0.3 \\
\hline 2 & $\mathrm{X}-2$ & 70 & 70.8 & 6.01 & 196 & 196 & 0.1 & 0.27 & 0.3 \\
\hline 4 & $X-4$ & 60 & 58.5 & 8.81 & 321 & 321 & 0.2 & 3.2 & 0.2 \\
\hline 5 & $X-5$ & 70 & 69.0 & 12.2 & 321 & 321 & 0.1 & 0.6 & 0.2 \\
\hline 6 & $\mathrm{X}-6$ & 75 & 74.4 & 14.2 & 321 & 321 & Out of limit & Out of limit & 0.3 \\
\hline 8 & $\mathrm{X}-8$ & 75 & 79.2 & 8.02 & 398 & 398 & 0.4 & 3.7 & 0.2 \\
\hline 9 & $X-9$ & 80 & 84 & 9.55 & 398 & 399 & 0.5 & 0.3 & 0.2 \\
\hline 10 & $X-10$ & 70 & 69.8 & 10 & 399 & 399 & 0.27 & 2.3 & 0.2 \\
\hline 11 & $\mathrm{X}-11$ & 75 & 75 & 7.75 & 309 & 309 & 0.5 & 0.5 & 0.4 \\
\hline 12 & $X-12$ & 60 & 59.7 & 8.36 & 310 & 310 & 0.3 & 7.1 & 0.2 \\
\hline 13 & $X-13$ & 70 & 69.8 & 7.31 & 1170 & 1170 & 0.3 & 0.13 & 0.2 \\
\hline 17 & $X-17$ & 60 & 64.7 & 3.05 & 245 & 246 & 0.5 & 0.13 & 0.2 \\
\hline 18 & $X-18$ & 60 & 57 & 4.00 & 276 & 276 & 0.31 & 2.0 & 0.3 \\
\hline 19 & X-19 & 75 & 79.3 & 4.45 & 267 & 267 & 0.3 & 8.3 & Out of limit \\
\hline 20 & $\mathrm{X}-20$ & 70 & 74.7 & 8.45 & 280 & 280 & 0.21 & Out of limit & $"$ \\
\hline 21 & $\mathrm{X}-21$ & 60 & 63.7 & 3.78 & 276 & 275 & 0.42 & 0.6 & 0.2 \\
\hline 22 & $\mathrm{X}-22$ & 60 & 66 & 6.37 & 323 & 326 & 0.3 & 3.9 & 0.2 \\
\hline 23 & $\mathrm{X}-23$ & 60 & 63.8 & 7.56 & 378 & 383 & 0.1 & 0.13 & 0.2 \\
\hline
\end{tabular}




\begin{tabular}{|c|c|c|c|c|c|c|c|c|c|}
\hline 24 & $X-24$ & 60 & 60.5 & 5.43 & 122 & 143 & 0.4 & 7.3 & 0.4 \\
\hline 25 & $\mathrm{X}-25$ & 70 & 73 & 6.77 & 167 & 201 & 0.5 & 0.3 & 0.25 \\
\hline 26 & $X-26$ & 60 & 63 & 4.41 & 100 & 101 & 0.3 & 4.2 & 0.2 \\
\hline 27 & $X-27$ & 60 & 57.2 & 3.70 & 345 & 345 & Out of limit & Out of limit & Out of limit \\
\hline 28 & $\mathrm{X}-28$ & 70 & 72.2 & 5.76 & 231 & 229 & 0.1 & 5.8 & 1.2 \\
\hline 29 & $\mathrm{X}-29$ & 75 & 77.7 & 8.59 & 278 & 278 & 0.3 & 0.3 & Out of limit \\
\hline 30 & $\mathrm{X}-30$ & 70 & 68 & 7.46 & 287 & 290 & 0.3 & 0.3 & $"$ \\
\hline 31 & $\mathrm{X}-31$ & 70 & 73 & 6.78 & 342 & 370 & 0.25 & 3.8 & $"$ \\
\hline 32 & $\mathrm{X}-32$ & 70 & 68.3 & 6.72 & 267 & 268 & 0.44 & 6.9 & 0.2 \\
\hline 33 & $X-33$ & 60 & 64.2 & 3.52 & 278 & 309 & 0.13 & Out of limit & Out of limit \\
\hline 34 & $X-34$ & 60 & 65.8 & 6.12 & 186 & 186 & 0.3 & 5.2 & 0.2 \\
\hline 35 & $\mathrm{X}-35$ & 60 & 64.3 & 5.90 & 235 & 235 & Out of Limit & Out of limit & Out of limit \\
\hline 36 & $X-36$ & 60 & 59.8 & 3.42 & 297 & 332 & 0.3 & 2.0 & 5.2 \\
\hline 37 & $X-37$ & 60 & 62.6 & 4.71 & 183 & 187 & 0.4 & 7.0 & 0.2 \\
\hline 38 & $\mathrm{X}-38$ & 60 & 63.7 & 4.73 & 230 & 231 & 0.23 & Out of limit & 0.84 \\
\hline 39 & $\mathrm{X}-39$ & 60 & 58.2 & 3.89 & 154 & 156 & 0.3 & 0.15 & Out of limit \\
\hline 40 & X-40 & 60 & 59 & 3.90 & 281 & 278 & 0.3 & 0.55 & 0.5 \\
\hline
\end{tabular}


From the investigation, it was found that $70 \%$ were within the limit and $30 \%$ crossed it (Table 1), thus showing that most of the installations achieved the limit. Remaining (30\%) installations should check it regularly and take precaution because a small change in tube voltage has greater effect on output radiation exposure and formation of final radiographic images and thereby it will be possible to reduce unwanted radiation exposure and poor quality diagnostic image.

The dose values in different diagnostic X-ray installations varied widely. Therefore, the installations should provide accurate output dose for radiation safety in diagnostic radiology.

Accuracy of exposure time measurement for diagnostic X-ray machine was investigated carefully as it directly affects the mAs and hence the amount of radiation emitted. The measurement was performed for different diagnostic X-ray installations. In this case tolerance limit is about $\pm 10 \%$ from the set value at control panel. It was found that $87.5 \%$ installations were within the limit and the rest $12.5 \%$ crossed it. In the present study almost all the X-ray installations provided enough accuracy in exposure timer.

Measurement of radiation dose level at patient waiting room showed that $92.5 \%$ installations had values within the limit and $7.5 \%$ exceeded it. The later cases demand adequate shielding arrangement around the X-ray room to ensure radiation safety in diagnostic radiology.

Considering radiation level at darkroom $85 \%$ X-ray installations were within the limit and $15 \%$ beyond it. In this case, most of the installations ensured radiation safety in dark rooms and a few installations which failed to achieve the recommendation level require additional barrier in order to ensure better radiation safety.

"Radiation level at control panel" was measured using Geiger Muller survey meter in different diagnostic $\mathrm{X}$-ray installations. The measured, $\mathrm{kVp}$ varied from $45 \mathrm{k}$ to $75 \mathrm{kVp}$ and $\mathrm{mA}$ varied from 30 to $320 \mathrm{~mA}$. From the study, it was found that $77.5 \%$ diagnostic $\mathrm{X}$-ray equipment were within the radiation dose limit and $22.5 \%$ failed to achieve the recommended value because of lack of perfect shielding around the control panel of diagnostic X-ray installations.

In this case almost all the installations were within the dose limit which is about $10 \mu \mathrm{Sv} / \mathrm{hr}$. The remaining $22.5 \%$ installations did not ensure radiation protection for workers.

\section{CONCLUSIONS}

Knowledge of the physical parameters which affect the production of radiographs and patient dose in X-ray diagnosis is important in achieving good healthcare. This study shows that the overall performance of different important radiographic parameters for 
radiation safety in X-ray diagnosis provide large variation. Therefore certain actions must be performed in order to improve equipment performance, image quality and to minimize patient doses and thereby it will be possible to provide safe and proper operation of the X-ray diagnosis system. Radiographers and X-ray technical officers should have the adequate training in the selection of procedures so as to ensure that doses to patients are as low as reasonably practicable to achieve the desired diagnostic objective. Lessons learned from this study should be fed back into the operating experience of departments to improve the quality of radiological services and also for the safety and performance of the systems to be improved. The methodology employed in this study shows that it is possible to create a database to evaluate both individual and collective impact of medical radiological practice in Bangladesh. More so the outcome of this study could be used as a guideline for any preventive measures to be taken in Bangladesh. Temperature, $\mathrm{pH}$ value and time for developing and fixing liquid must be carefully measured to eliminate improper film processing techniques. X-ray tube voltage and radiation exposure time for diagnostic X-ray machines should be checked to minimize deleterious effects of ionizing radiation. In diagnostic radiology, radiation dose level at patient waiting room, dark-room and around control panel should not exceed the dose limits. This is necessary to protect patients, workers and public.

\section{REFERENCES}

Freitas, M. B. and Yoshimura, E. M. 2003. An overview of doses to patients and irradiation conditions of diagnostic chest X-ray examinations carried out in hospitals of the city of Sao Paulo, Brazil. Radiation Protection Dosimetry 103: 141-148.

Hamed, A. A. Elshirbiny, N. and Nassef, M. H. 1999. Study of radiation exposure dependence on the physical parameters of medical diagnostic X-ray machines. Radiation Protection Dosimetry 82: 277-283.

International Commission on Radiological Protection, (ICRP), ICRP-60 (1990): Recommendations of the International Commission on Radiological Protection, Annals of the ICRP. 1990. Pergamon Press, Oxford 21 (1-3).

Muhogora, W. E. and Nyanda, A. M. 2001. The potential for reduction of radiation doses to patients undergoing some common X-ray examinations in Tanzania. Radiation Protection Dosimetry 94(4): 381- 384.

Rehani, M. M. 1995. Diagnostic Imaging Quality Assurance. Jaypee Brothers Medical Publishers (P) Ltd., First Edition.

Sandstrom, S., Ostensen, H., Pettersson, H. and Akerman, K. 2003. The WHO manual of diagnostic imaging: radiographic technique and projections. Published by the World Health Organization in collaboration with the International Society of Radiology. 26.

Schandorf, C. and Tetteh, G. K. 1998. Analysis of the status of X-ray diagnosis in Ghana. The British Journal of Radiology 71: 1040-1048.

Warren-Forward, H. M. and Mckeeney, D. B. 1992. Towards reduction of patient exposure in medical diagnostic radiology. Radiation Protection Dosimetry 43: 283-286. 